\title{
POSSÍVEIS ABORDAGENS PARA UM ESTUDO SOBRE COLEÇÕES MUSEOLÓGICAS DE FOTOGRAFIA
}

Carolina Soares ${ }^{1}$

\section{Resumo}

$\mathrm{Na}$ constituição de uma coleção museológica de obras de arte, as escolhas estão pautadas na relevância histórica do nome do artista, do período, da técnica, do estilo. De acordo com os historiadores Giulio Carlo Argan e Maurizio Fagiolo, uma obra é vista como obra de arte quando tem importância na história da arte e contribui para a formação e desenvolvimento de uma cultura artística. E a constituição de uma coleção museológica de fotografias, em quais critérios estão pautadas as escolhas? De que modo a história da fotografia está articulada à história da arte? Como objeto de análise está a Coleção PirelliMasp de Fotografia, a partir da qual proponho pensar de que modo são elaborados discursos para a inserção de imagens fotográficas em uma determinada cultura artística moderna.

Palavras-chave: Fotografia - Arte - História da Arte - História da Fotografia - Museu

\begin{abstract}
In the conception of a museum art collection, the selections are made by historical relevance of the artist's name, period, technique, style. According to the historians Giulio Carlo Argan and Maurizio Fagiolo, a piece of work can be seen as art when it becomes important for the history of art and contributes to the constitution and the development of an artistic culture. And, what about the criterions to conceive a museum photography collection? How is the history of photography articulated with the history of art? To discuss that subject matter, I will take as an example the Collection Pirelli-Masp of Brazilian photographers. My purpose is to think about how the debates are elaborated for the introduction of photographic images into a modern artistic culture.
\end{abstract}

Keywords: Photography - Art - History of Art - History of Photography - Museum

$\mathrm{Na}$ constituição de uma coleção museológica de obras de arte, as escolhas estão pautadas na relevância histórica do nome do artista, do período, da técnica, do estilo. De acordo com os historiadores Giulio Carlo Argan e Maurizio Fagiolo, uma obra é vista como obra de arte quando tem importância na história da arte e contribui para a formação e desenvolvimento de uma cultura artística. ${ }^{2}$

A história da arte adquire, assim, a função de estudar a arte não como um reflexo, mas como agente da história que opera num campo próprio, a partir de metodologias singulares. Para Argan e Fagiolo, torna-se relevante o fato da história da arte enquadrar-se na história geral da cultura, explicando como será a cultura elaborada e construída pela arte.

E a constituição de uma coleção museológica de fotografias, em quais critérios estão pautadas as escolhas? De que modo a história da fotografia está articulada à história da arte? Seria possível realizar uma leitura da história da fotografia a partir das questões postas por Argan e Fagiolo?

Como objeto de análise está a Coleção Pirelli-Masp de Fotografia, a partir da qual proponho pensar de que modo são elaborados discursos para a inserção de imagens

\footnotetext{
${ }^{1}$ Mestranda em História da Arte pela ECA/USP; Integrante do Grupo de Estudos em Arte\&Fotografia da ECA/USP; Integra o grupo de críticos de arte do Centro Universitário MariAntonia/USP; Pesquisadora do Departamento de Curadoria MAM/SP.

2 ARGAN, Giulio Carlo e FAGIOLO, Maurizio. Guia de História da Arte, Lisboa: Ed. Estampa, 1994.
} 
fotográficas em uma determinada cultura artística moderna. Parto da hipótese de que esse posicionamento pode resultar em um esforço para conceder à fotografia o status de arte, mediante a transformação da cópia fotográfica em mercadoria privilegiada e do fotógrafo em autor autônomo.

A discussão internacional em torno da inserção da fotografia nos museus de arte, na primeira metade do século XX, ganha fôlego com a inauguração, em 1929, do Museu de Arte Moderna de Nova York (MoMA), onde a fotografia é reconhecida enquanto prática artística moderna.

Neste período, afirmava-se o caráter artístico e autônomo da imagem fotográfica, embora ainda fossem conservados alguns legados pictorialistas como a cópia pura, a edição limitada, o uso de técnicas artesanais de impressão e outras estratégias para distinguir a fotografia artística da infinidade de imagens produzidas em massa.

No cenário da fotografia norte-americana, essas questões estão representadas pelo trabalho crítico dos sucessivos conservadores de fotografia do MoMA - iniciado por Beaumont Newhall e culminado por John Szarkowski. A legitimação da straight photography estará pautada nos mesmos argumentos formulados pela crítica da arte moderna, que se materializa nos textos de Clemente Greenberg e Michael Fried: a autonomia das disciplinas artísticas que seguem sua própria especificidade técnica, sua pureza, a originalidade e singularidade do autor.

O esforço empreendido por Newhall, por exemplo, estava direcionado para a compreensão do "mérito estético" da fotografia. Para ele, a história da fotografia podia ser resumida como uma sucessão de inovações técnicas que deveriam ser julgadas por suas conseqüências estéticas. Defendia que cada cópia seria uma expressão individual do fotógrafo, colocando-se contra a visão simplesmente mecanicista do meio. ${ }^{3}$

$\mathrm{Na}$ busca da definição de uma autêntica criatividade fotográfica, Newhall elaborou um sistema comparativo de classificação das cópias fotográficas, a partir de categorias das artes plásticas. Assim, forjou uma suposta autenticidade fotográfica ora baseada em interpretações objetivas, ora abstratas. Tentava criar um cânon e uma história da arte para fotografia, construída a partir de uma suposta 'expressão criativa'. ${ }^{4}$

Com esse discurso legitimador, o campo, antes plural, da fotografia foi reduzido a uma estética única e abrangente. ${ }^{5}$

A contextualização a partir de um recorte internacional revela que as aproximações com o universo da pintura não são singulares às imagens fotográficas presentes na Coleção Pirelli-Masp de Fotografia, pelo contrário. Mesmo estando a história da fotografia brasileira ainda em processo de estruturação, podemos pensar as decisões dos membros de seu Conselho Deliberativo como pautadas em possíveis ideais estéticos apropriados das Belas Artes.

Para a constituição de um cânon, explica-se a história da fotografia, de maneira recorrente, por meio da evolução de estilos ou de ensaios biográficos que identificam o fotógrafo como autor. Seguem-se modelos para encontrar um sistema legítimo para que a

\footnotetext{
${ }^{3}$ Esta reinscrição da fotografia dentro do vocábulo tradicional das artes plásticas foi defendida - no cenário institucional norte-americano - não apenas por Newhall, mas também pelo colecionador David Hunter McAlpin e pelo fotógrafo Ansel Adams. Ver PHILLIPS, Christopher. 'El tribunal de la Fotografía'. In BOLTON, Richard (org.), The Contest of Meaning: Critical Histories of Photography, Cambridge, 1989.

${ }^{4}$ Ibid p.81.

${ }^{5}$ CRIMP, Douglas. 'El viejo tema del museo, el nuevo tema de la biblioteca', in Catálogo Los usos de la imagen - fotografía, film y video en la coleccion Jumex, Malba, Buenos Aires, 2004.
} 
fotografia ocupe espaços arquitetônicos e culturais reservados à pintura. A aplicação de critérios estilísticos e autorais à fotografia, muitas vezes, confunde-se com um intuito histórico de produzir grande impacto ao atribuir à imagem fotográfica sofisticação tanto discursiva quanto técnica.

Para Argan e Fagiolo, a identificação do estilo pode levar à atribuição, o que coloca a obra no preciso âmbito cultural em que foi realizada. Para isso, "[...] não basta verificar analogias temáticas ou formais; é necessário reconstruir o processo de desenvolvimento de uma cultura figurativa, tendo em vista que nela se operam freqüentemente mudanças"..

Desse modo, para aplicar o termo estilo à cultura figurativa contemporânea, é necessário compreender as transformações conceituais que o próprio termo tem sofrido principalmente a partir da segunda metade do século XX. Na medida em que a arte assimilava todas as técnicas e todos os materiais possíveis sem nenhuma interdição de princípio - recusando assim qualquer especificidade e rompendo com a tradição -, a noção de estilo foi deixando de ser evocada para definir a singularidade característica do ofício ou o vocabulário formal de seus autores.

No caso da atribuição dos termos 'autor' e 'estilo' ao conjunto de fotografias da Coleção Pirelli-Masp parece uma tentativa de criar a condição necessária para que o meio em questão possa ser considerado como gerador de arte. Os membros do Conselho Deliberativo apóiam seus discursos nessas concepções para justificarem a subjetividade e originalidade da fotografia. Essa atitude acaba por tornar-se legítima pelo fato de estar relacionada a uma coleção de um museu onde é necessário identificar a presença do artista na obra para ter sua autenticidade reconhecida.

\section{$* * * *$}

Pela história da arte, a concepção de autor provém de uma crença de que tudo quanto compõe uma imagem original é uma expressão dos sentimentos e pensamentos interiores de seu criador. Incluem-se aí as pinceladas do artista - sua densidade e variação bem como a fisionomia peculiar conferida por ele aos objetos e sua forma de modelar o espaço que os mesmos ocupam.

De maneira crítica, Rosalind Krauss analisa a questão:

A totalidade da pintura original parece-nos carregar o autógrafo de seu criador; a importância que tem para nós reside na autenticidade com que traz a marca de seu próprio ser. É nesse sentido que parece haver uma correspondência entre o espaço da imagem que podemos enxergar e o espaço interior, psicológico e, portanto, invisível, do autor da imagem. ${ }^{7}$

Para Krauss, essa é uma visão que não mais corresponde ao debate artístico contemporâneo. Contudo, essa busca pelo original está dentre os objetivos dos discursos dos membros do Conselho Deliberativo da Coleção, que tentam perceber na fotografia o "autógrafo de seu criador", ainda que para isso seja necessário aplicar conceitos que fogem à especificidade do próprio meio fotográfico.

Para o reconhecimento de sua autenticidade, a fotografia é submetida ao julgamento dos membros do Conselho que acabam por assumir a postura do connoisseur, cujo trabalho é tentar garantir a originalidade da obra. A partir de mecanismos da história da arte e da museologia, é realizada a análise do estilo e da autoria para a subjetivação das fotografias.

Para Rubens Fernandes Jr., membro do Conselho Deliberativo da Coleção PirelliMasp:

\footnotetext{
${ }^{6}$ ARGAN e FAGIOLO, op cit. p.25.

${ }^{7}$ KRAUSS, Rosalind. Caminhos da Escultura Moderna, São Paulo: Martins Fontes, 1998, p.87.
} 
É interessante percebermos o quanto a fotografia brasileira evoluiu, principalmente nos últimos anos. Essa valorização da fotografia é conseqüência, finalmente, do reconhecimento de sua importância no mundo das artes visuais, tanto do ponto de vista de memória e identidade, como de sua especificidade estética. $^{8}$

Ao contrário do que afirma Fernandes Jr., talvez seja exatamente por não possuir regras estéticas próprias, que a fotografia toma por empréstimo questões e conceitos presentes em movimentos artísticos aos quais muitos fotógrafos reivindicam pertencer. A ausência de um discurso crítico sobre a fotografia permite a apropriação de pressupostos das artes plásticas.

Isso explicaria, por exemplo, o fato de Rubens Fernandes Jr. afirmar - no texto do segundo catálogo da Coleção - que, na história da fotografia, inúmeras tendências e estilos são possíveis de serem encontradas: "Do primitivo pictorialismo até o surrealismo, a documentação realista, o abstrato, o pop, o conceitual, o expressionismo, a nova objetividade e todos os neos e pós"?

Assim, é constituída uma determinada história para a fotografia tomando como parâmetro a história das artes plásticas, mais especificamente da pintura, cujas categorias podem pressupor uma relação orgânica do conjunto de obras de um pintor, em sua totalidade, com escolas e tradições.

De acordo com Krauss, o fato de ser múltipla em razão de sua própria técnica, a fotografia reforça a idéia de que, teoricamente, todas as imagens do mesmo sujeito sejam, no fundo, a mesma imagem, e, assim, participem da repetição pura e simples. E é essa multiplicidade que dificulta o emprego da noção de originalidade como conceito estético da prática fotográfica, pois para ser aplicado depende exatamente da noção de diferença. ${ }^{10}$

Ao atribuir à fotografia 'tendências e estilos' das artes plásticas, o discurso de Fernandes Jr. reafirma os modos pelos quais uma determinada história da fotografia é constituída.

Contudo, é necessário não deixar de lado a complexidade na análise de fotografias a partir da noção de 'escola'. Como explica Sontag, os movimentos na história da fotografia são rápidos, às vezes puramente adventícios, e "nenhum fotógrafo será melhor compreendido por ser membro de um grupo". Analisa que "agrupar fotógrafos em escolas ou movimentos parece uma espécie de equívoco baseado na analogia [...] invariavelmente enganadora entre fotografia e pintura". ${ }^{11}$

Essas questões podem ser problematizadas mesmo quando aplicadas à pintura. No entanto, na fotografia, tornam-se mais complexas por ela não estar pautada em uma mesma tradição secular que determina o cânon das belas-artes.

Pensar a fotografia como jornalística, documental, publicitária e mesmo conceitual está menos vinculado a uma definição de 'escola' e mais a uma possibilidade de entendê-la a partir de sua especificidade técnica presente na captura de uma suposta realidade. E é nessa representação de um referente que sua apreciação estará inicialmente pautada. Para o estudioso francês Pierre Bourdieu, a natureza do tema, o assunto fotografado torna-se uma primeira questão para se estabelecer um julgamento sobre a imagem fotográfica. ${ }^{12}$

\footnotetext{
${ }^{8}$ FERNANDES Jr., Rubens. Catálogo Coleção Pirelli-Masp de Fotografia, São Paulo:Masp, 2002, p.6.

${ }^{9}$ FERNANDES Jr., Rubens. Catálogo Coleção Pirelli-Masp de Fotografia, São Paulo:Masp, 1992, p.6.

${ }^{10}$ KRAUSS, Rosalind. O Fotográfico, Barcelona: Gustavo Gili, 2002, p.223.

${ }^{11}$ SONTAG, Susan. Ensaios sobre a Fotografia, Rio de Janeiro: Arbor, 1981, p.137.

12 BOURDIEU Apud KRAUSS. op. cit., p.222.
} 
A análise da fotografia a partir de seu tema - seja uma paisagem, um retrato, um nu, entre outros - tornou-se, ao longo de sua história, recorrente. Contudo, a questão que se coloca é a de entender que mesmo esse julgamento ganha eficácia por trazer para a imagem fotográfica uma tradição pictórica. Embora legítima, essa forma de análise adquire complexidade quando percebida como algo próprio e inerente à fotografia, deixando de lado dados históricos que indicam o contrário.

Os primeiros ensaios fotográficos do século XIX, por exemplo, podem revelar que, de início, o novo invento se pauta, sobretudo, em um repertório derivado da tradição pictórica - retratos, paisagens, naturezas-mortas.

De acordo com Annateresa Fabris:

Se tal imagística é uma conseqüência natural da derivação artística dos primeiros fotógrafos, não se podem esquecer, porém, as razões técnicas que estão na base dessa atitude. Os longos tempos de exposição e a conseqüente necessidade de imobilidade do modelo faziam com que a fotografia tivesse que restringir o alcance de suas possibilidades de registro, conformando-se, a princípio, a composições já consolidadas no imaginário artístico da sociedade oitocentista. ${ }^{13}$

No entanto, ao longo do século XX e XXI, a fotografia sofre transformações tanto técnicas quanto teóricas, que possibilitam discussões sobre a natureza do meio e a conseqüente busca por um discurso próprio.

A distinção entre 'gêneros', na fotografia, torna-se ainda problemática quando diante de imagens que podem ser jornalísticas e documentais. Afinal, quais os critérios que as diferenciam? E até que ponto tal segmentação contribui para uma melhor compreensão sobre o meio? Nesse sentido, a fotografia - diferente da pintura e da literatura - parece fugir a categorias de gêneros relacionadas com tradições históricas que detêm critérios de auto-regulação bastante fortes. ${ }^{14}$

Tomando como exemplo as fotografias de Juca Martins e de Mário Cravo Neto, presentes no primeiro catálogo da Coleção, é possível perceber dois fotógrafos cuja qualidade técnica e inventividade dos trabalhos são indiscutíveis, mas suas produções suscitam questões diferentes sobre a própria fotografia.

Enquanto no trabalho de Martins prevalece a perspicácia no registro, no corte fotográfico; no de Cravo Neto, a discussão volta-se para a contaminação da fotografia por um determinado universo sócio-cultural.

Ao apontar diferenças entre os trabalhos desses fotógrafos, não se pretende estabelecer uma distinção entre os gêneros fotográficos presentes na Coleção, pois seria uma tentativa de categorização que a própria fotografia parece desautorizar.

Apesar de recorrentes tentativas como o pictorialismo, a fotografia de vanguarda dos anos de 1920 ou as tentativas mais recentes de integração da fotografia às artes plásticas, falta cristalização nas tradições que a auto-regulem. De acordo com Schaeffer, o termo gênero não deve ser aplicado à fotografia como sendo um sistema organizado de normas relacionadas entre si, dando lugar a um horizonte fortemente axiológico. ${ }^{15}$

Desse modo, já não se pode falar de gêneros em um sentido estrito. As categorias passam a ser passíveis de crítica pelo fato de serem muitas vezes estabelecidas de forma arbitrária, o que as tornam instrumentos de identificação.

13 FABRIS, Annateresa (org.). 'A fotografia e o sistema das artes plásticas'. In Fotografia - Usos e Funções no século XIX, São Paulo: Edusp, 1998, p.174.

14 Ver SCHAEFFER, Jean-Marie. 'La fotografía entre visión e imagen'. In ARBAÏZAR, Philippe \& PICAUDÉ, Valérie (org.), La Confusión de los Géneros en Fotografía, Barcelona: Gustavo Gili, 2004.

15 Ibid p. 20 . 
Zé do Boni, também membro do Conselho Deliberativo da Coleção, no texto do quarto catálogo, exclama: “A fotografia virou arte, definitivamente!”. Tal exaltação está relacionada ao fato de a Coleção consolidar seu espaço no Masp, fato justificado por Boni a partir de argumentos que põem em paralelo a qualidade das fotografias selecionadas e a subjetividade do fotógrafo:

[...] enquanto se pode destacar esta coleção como a primeira vez que um grande museu brasileiro tem uma política sistemática neste aspecto, ela se consolidará muito mais pela importância e pela qualidade do conteúdo reunido: a obra de artistas brasileiros, nativos ou adotivos, conforme o nosso peculiar sentido de nacionalidade, que se valem da fotografia como canal de transmissão da sua personalidade, intelecto e sentimento. ${ }^{16}$

Ao longo de seu texto, o autor aborda o fato de a 'fotografia ter virado arte' e aponta para questões fundamentais do debate artístico travado nas últimas décadas do século XX, centrado numa inversão de pontos de vista que indicavam com clareza que não se tratava tanto de encarar a fotografia contemporânea como arte, mas antes a arte contemporânea como marcada em seus fundamentos pela fotografia. ${ }^{17}$

Naquele momento, no entanto, esse discurso ganha importância e legitimidade, pois é quando a fotografia está sendo institucionalizada no Brasil, processo iniciado principalmente com o surgimento do Masp, e sedimentou-se com a Coleção. Para isso, ao Museu passava a ser atribuída não apenas a responsabilidade de resguardar uma determinada memória fotográfica, mas de estruturar um discurso para sua aceitação e permanência como arte.

Boni ressalta um ponto importante para a compreensão da necessidade do reconhecimento do autoral na fotografia.

A questão existencial fotografia-arte sempre foi orientada pela competição por uma área de influência e pela defesa de um mercado. Este sempre foi dependente de rótulos para definir estilos e de artifícios para valorizar autores. Paradoxalmente, embora seja uma forma importante de viabilizar e sustentar a produção de artistas, é o próprio mercado que derruba o sentido mais elevado da arte, reduzindo-a ora a mero objeto decorativo, ora a simples mercadoria. Quando uma obra passa a ter mais interesse em função do valor do seu investimento, quando um comprador toma decisões em função de indicadores de natureza econômica, quando um artista escolhe o tema e o estilo impulsionado por modismos convenientes, toda criação humana é banalizada. ${ }^{18}$

A parceria entre empresa privada e museu já pode ser um argumento para a inserção da Coleção Pirelli-Masp em uma lógica de mercado, pois o que define a aquisição das obras é o financiamento disponível, pré-requisito necessário para que as fotografias possíveis de serem compradas recebam a autenticação discursiva do autoral como valor artístico.

No cenário internacional norte-americano, esse mercado, já na primeira metade do século XX, encontrava-se em fase de constituição. No Brasil, será por volta dos anos de 1970 que galerias especializadas, museus e fotógrafos começam a pensar, de maneira mais profissional, sobre o caráter mercadológico da fotografia-arte. É nesse período, por exemplo, que fotógrafos como Sebastião Salgado e Miguel Rio Branco dão início às suas carreiras internacionais, o que repercute de maneira positiva para o desenvolvimento do mercado nacional.

${ }^{16}$ BONI, Zé de. Catálogo Coleção Pirelli-Masp de Fotografia, São Paulo: Masp,1994, p.6.

${ }^{17}$ DUBOIS, Philippe. O Ato Fotográfico, Campinas: Papirus, 1994.

${ }^{18}$ BONI, Zé de. Catálogo Coleção Pirelli-Masp de Fotografia, São Paulo: Masp, 1994, p.6. [sic] 
Final dos anos de 1960, a existência de um inexpressivo mercado artístico fotográfico gerou propostas como o movimento Photogaleria em São Paulo e no Rio de Janeiro. Galerias associadas a escolas como a Enfoco surgiram como uma das primeiras opções. Na década de 1970, surgem iniciativas privadas e públicas que favoreceram o crescimento do mercado. No período de 1980, são inauguradas a Casa da Fotografia Fuji e a Collector's e surge o NAFOTO, que se torna responsável pela realização dos eventos bienais do 'Mês da Fotografia', iniciados em 1993. ${ }^{19}$

A partir de uma análise geral, o que se percebe no cenário artístico fotográfico brasileiro são tentativas, algumas mais bem sucedidas que outras, de firmar um mercado que se consolida na Coleção Pirelli-Masp. No Brasil, é a primeira experiência pautada em atividades sistemáticas sustentadas por uma base estrutural constituída pela união entre o apoio financeiro da Pirelli, a tradição artística do Masp e a credibilidade dos membros do Conselho Deliberativo.

${ }^{19}$ MENDES, Ricardo. Li Photogallery: falando de espaços expositivos In site www.namata.com.br 